\title{
Artificial family selection based on growth rate in cultivated lines of Litopenaeus vannamei (Decapoda, Penaeidae) from Venezuela
}

\author{
Marcos De Donato ${ }^{1}$, Raúl Ramirez ${ }^{2}$, Chris Howell ${ }^{2}$, Roberto Verginelli ${ }^{2}$, Tomás Orta ${ }^{2}$, \\ Saúl Cabrera ${ }^{2}$, Enrique Mata ${ }^{2}$ and Ramón Manrique ${ }^{2}$ \\ ${ }^{1}$ Laboratorio de Genética Molecular, Departamento de Biomedicina, Instituto de Investigaciones \\ en Biomedicina y Ciencias Aplicadas, Universidad de Oriente, Cumaná, Venezuela. \\ ${ }^{2}$ Aquamarina de la Costa Shrimp Farm, Santa Fe, Sucre, Venezuela.
}

\begin{abstract}
We investigated the effects of family selection on the growth rates of four genetic lines of Litopenaeus vannamei, the Pacific white shrimp, from Venezuela. The mean family weight at selection was $16.79 \mathrm{~g}$ and the mean growth rate was $0.169 \mathrm{~g} \mathrm{~d}^{-1}$ at a mean age of 138 days. The mean growth rates per generation were $0.141 \mathrm{~g} \mathrm{~d}^{-1}$ for the parental generation $\left(P_{0}\right), 0.173 \mathrm{~g} \mathrm{~d}^{-1}$ for the $F_{1}$ and $0.191 \mathrm{~g} \mathrm{~d}^{-1}$ for the $F_{2}$. Survival varied from $83.3 \%$ to $94.4 \%$. There were statistically significant differences between lines, with lines $\mathrm{B}$ and $\mathrm{C}$, growing at higher temperatures and lower salinities, showing the fastest growth. Regression analysis between growth rate and age for each genetic line showed high $r^{2}$ values, but smaller than those shown between growth rate and generation. The mean heritability $\left(h^{2}\right)$ estimated for growth rate was $0.25 \pm 0.04$, with line per generation values ranging from 0.18 to 0.38 . The mean heritability for growth rate per line showed some variation but there was no correlation between heritability and growth rate. Females showed a greater gain in growth rate per generation than males due to their faster growth when they were older. This study shows the high potential of these $L$. vannamei populations for the future of shrimp culture in the Americas.
\end{abstract}

Key words: family selection, genetic improvement, growth rate, Litopenaeus vannamei.

Received: September 10, 2007; Accepted: March 8, 2008.

\section{Introduction}

The worldwide decline in ocean fisheries stocks has provided impetus for a rapid growth in aquaculture activities, and the contribution of aquaculture to global supplies of aquatic species has grown from about $5 \%$ of total production by weight in 1970 to $38 \%$ in 2004 (Fisheries Global Information System), increasing an average of $8.7 \%$ per year. In terms of global aquaculture production, the total volume of cultured penaeids increased from $1.6 \%$ in 1970 to $36 \%$ in 2004 at an average rate of $12 \%$ per year.

The vast majority of farmed animals are produced using low performing wild or cultured stocks, which often suffer from genetic inferiority due to the erosion of genetic variability (genetic drift) and inbreeding. In 1993, less than $1 \%$ of world aquaculture production was based on broodstock originating from selective breeding programs

Send correspondence to Marcos De Donato. Laboratorio de Genética Molecular, Departamento de Biomedicina, Instituto de Investigaciones en Biomedicina y Ciencias Aplicadas, Universidad de Oriente, Cerro del Medio, Cumana 6101, Venezuela. E-mail: marcosdedonato@yahoo.com.
(Gjedrem, 1997). However, in recent decades, substantial genetic improvement and increases in production efficiency have been achieved in some farmed fish species such as salmonids and tilapia (Hulata, 2001). This improvement has been achieved through the implementation of quantitative genetic principles facilitated by improved animal tagging systems. Growth rate was the first trait targeted for improvement by selective breeding due to its relation to production, but since there have been tremendous losses in salmonids and marine shrimp production due to infectious diseases, there is an increasing demand for disease resistant animals.

Early work on the genetics of economically important traits in Penaeids was related to domestication and culturing in closed cycles (AQUACOP, 1983; Lester, 1983). This work led to the establishment of breeding programs and the study of growth related traits (Lester, 1988; Goswani et al., 1990; Huang et al., 1990; Wyban, 1992). Recent efforts have focused on artificial selection for growth and growth related traits and resistance to virus infection (Argue et al., 2002; Coman et al., 2002; Goyard et al., 2002; Gitterle et al., 2005a, b; Kenway et al., 2006). 
Venezuelan populations of Litopenaeus vannamei (formerly Penaeus vannamei) (Decapoda, Penaeidae), commonly called the Pacific white or whiteleg shrimp, although technically a prawn, have demonstrated a high growth potential for culture due to their performance in the production systems and, more importantly, the sanitary quality of their hatcheries, and are the only non-native populations used for breeding programs in Brazil, Colombia and Mexico (CENIACUA, 1999; Hernandez, 2002; $\mathrm{ABCC}, 2003)$.

During the study described in this paper we analyzed growth and survival data of three generations to evaluate the response to the family selection practiced in the genetic selection program applied to four lines of a domesticated strain of $L$. vannamei from Venezuela.

\section{Materials and Methods}

The study was undertaken from November 1999 through February 2003 at two sites belonging to Aquamarina Shrimp Farm, one located in the Venezuelan town of Unare, Anzoategui state (ponds), and the other in Santa Fe, Sucre state (hatchery). We carried out family selection on four lines (denoted A, B, C and D) of a cultivated strain of $L$. vannamei which had been grown under closed cycle conditions for more than nine years, using a mass selection program in order to improve growth performance (De Donato et al., 2005). Family selection was used over the other types of selection schemes because it maintains control of the crossing and relationships between individual $L$. vannamei.

During the study, the water temperature ranged from $27^{\circ} \mathrm{C}$ to $34^{\circ} \mathrm{C}$, salinity from $2.5 \%$ to $3 \%$ and oxygen concentration was always within the normal range of $2.5 \%$ to $3 \%$. The lines were maintained separately for their use as reproductive stock at different times during the year, with line A being grown from February to May $\left(29{ }^{\circ} \mathrm{C}\right.$ mean temperature, $2.9 \%$ salinity), line B from April to July $\left(31{ }^{\circ} \mathrm{C}, 2.7 \%\right)$, line $\mathrm{C}$ from June to September $\left(33^{\circ} \mathrm{C}, 2.6 \%\right)$ and line D from December to March $\left(27{ }^{\circ} \mathrm{C}, 3 \%\right)$. We selected an average of 46.5 families for each line and generation (ranging from 36 to 50), for a total of 558 families analyzed. Some of the families were discarded due to bacterial or fungal infections.

Selection was carried out on up to 50 full-sib families by mating matured males and females using artificial insemination. All the families were generated within two to three days of each other. From each mating, we randomly selected 6000 nauplii and raised them in 40-litre fiberglass tanks at a nauplii density of $150 \mathrm{~L}^{-1}$ in previously purified sea water at a salinity of $3.5 \%$. The sea water was purified by mechanical filtration and UV light treatment. The nauplii were fed with microalgae of the species Chaetoceros gracilis (stocks maintained at Aquamarina de la Costa, Santa Fe, Sucre, Venezuela) plus a commercial liquid larval diet (Liqualife, Cargill, USA) and Artemia nauplii (San
Francisco Bay, USA) according to a standard protocol (FAO, 2003), with monitoring of viability and environmental temperature.

The larvae were raised to the post-larval (PL) stage with a minimum size of $5 \mathrm{~mm}$ to $6 \mathrm{~mm}$ (usually to stages PL8 to PL12) and then shipped $120 \mathrm{~km}$ in 10-litre bags containing sea water and pure oxygen at a temperature of $18^{\circ} \mathrm{C}$ to a pond facility at Unare, where they were placed in PVC cages with a polyester fabric mesh inside two 60000-litre concrete tanks ( 25 cages per tank) at a density of 400 larvae per cage and fed commercial diets (PL granulates, Zeigler Bros., Inc., USA) with a $40 \%$ protein content for from five to six-and-a-half weeks. At this stage, a random sample of 30 juveniles from each family was counted and individually weighed to determine initial weight (stocking weight) and 150 juveniles from each family were labeled at the abdominal somites using the elastomer tagging system developed by Northwest Marine Technologies Inc. (Washington, USA) and stocked together in a concrete tank at a density of $144 \mathrm{~m}^{-2}$. The juveniles were fed a commercial pond pellet diet containing $35 \%$ protein (AQUALINE, Purina, Venezuela). The tank had a constant air supply and the levels of oxygen, ammonia and nitrites were monitored on a regular basis. Random samples of $30 \mathrm{~L}$. vannamei from the whole population were weighed every week to monitor growth and to adjust the feeding level. After 12 to 14 weeks in the tank, the shrimps were harvested, separated by family in cages. From each family, 32 shrimps (16 males and 16 females) were weighed. Family survival was calculated from the total number of $L$. vannamei harvested.

Weight data on families were analyzed using the Multiple Trait Derivative Free Restricted Maximum Likelihood (MTDFREML) program to estimate the breeding value, variance components and heritability $\left(h^{2}\right)$, using an animal model with sex as a fixed effect and growth rate as a simple character with restricted maximum likelihood calculations (Boldman et al., 1995). Also, full pedigree information was included in the dataset. No environmental effects were considered in the model. Fifteen of the families with the highest mid-parent breeding values, based on the growth rate of progeny, were selected as broodstock to produce the next generation of larvae. Analysis of the relationships between growth related parameters and other factors was carried out using t-tests, analysis of variance (ANOVA) calculating its coefficient $(\mathrm{F})$ as the the proportion of the intergroup square mean on the intragroup square mean (error), and Pearson's regression analysis, calculating the Pearson's regression coefficient $\left(r^{2}\right)$ and correlation coefficient $(\rho)$, as implemented in the SPSS Software Package, version 11.5.1 (SPSS Inc., USA).

After data analysis and determination of the best performing families, the selected families were again placed in a sixty-ton concrete tank and cultivated for another 21 to 25 weeks, using the same feeding and sampling scheme, at a density of $45 \mathrm{~L}$. vannamei $\mathrm{m}^{-2}$. After this 
period the animals were returned to the hatchery facility and were maintained in circular concrete tanks with aeration at a density of 6 individuals $\mathrm{m}^{-2}$ until they reached sexual maturity. The new 50 families were formed by mating males and females from the selected families as previously described. To decrease the effect of inbreeding, the crosses were carried out using families that were not related. No intrafamily selection was carried out and the mature $L$. vannamei were chosen at random.

\section{Results}

The mean of family means for weight at stocking was $1.83 \mathrm{~g}$, and the mean of family means for final weight was $16.79 \mathrm{~g}$, for an mean growth rate of $0.169 \mathrm{~g} \mathrm{~d}^{-1}$, grown for an average of 89.2 days (Table 1). Survival, although it varied among families in each line and generation, was high and ranged from $83.3 \%$ to $94.4 \%$ (Table 1), with the differences between sexes, lines or generations being very small and not statistically significant $(F=0.32, p=0.7276)$. Survival did not statistically affect growth rate $(\mathrm{F}=1.77$ $\left.(\mathrm{p}=0.1845), r^{2}=0.007\right)$, even though there could have been, theoretically, a relationship between these two factors because of the effect of survival on $L$. vannamei unit density. The average female to male sex ratio was $1.04 \pm 0.02$ with a range of 0.42 to 2.00 .

The L. vannamei were harvested after 84 days to 98 days in the tanks and the mean of the family means for weight and growth rate was found to be statistically higher in females than males $(\mathrm{t}=5.27, \mathrm{p}<0.001 ; \mathrm{t}=5.25$, $\mathrm{p}<0.001$; respectively). Furthermore, the final weight and growth rate regression coefficient $\left(r^{2}\right)$ and correlation coefficient $(\rho)$ between females and males were high, being $r^{2}=0.842$ and $\rho=0.918$ for final weight and $r^{2}=0.859$ and $\rho=0.927$ for growth rate. Regression analyses between growth and age using the data for all individual $L$. vannamei and including separate analyses for each sex showed $r^{2}$ values varying from 62.4 to 65.9 (Figure 1), with the slopes of the curve for each sex showing statistically significant differences so that the older the $L$. vannamei the larger was the difference between the mean weights of females and males. We found statistically significant differences among generations in regard to both mean final weight $(\mathrm{F}=717.7$, $\mathrm{p}<0.0001)$ and mean growth rate $(\mathrm{F}=2907.1, \mathrm{p}<0.0001)$, with the growth rate in each line being the lowest for $\mathrm{P}_{0}$ and the highest for $\mathrm{F}_{2}$ (Figure 2). Regression analysis between the growth rate and age for each generation showed high $r^{2}$ values of around $90 \%$ and a comparison between the slopes of the curves for each generation showed that $\mathrm{P}_{0}$ had the lowest slope and $\mathrm{F}_{2}$ the highest. The coefficient of variation (CV), a measure of the variability in final weight, showed a decreasing trend in each generation, with the $\mathrm{CV}$ varying from $16.02 \mathrm{~g}$ to $13.35 \mathrm{~g}$ for females and from $13.51 \mathrm{~g}$ to $12.36 \mathrm{~g}$ for males, although it was only statistically significant in the females from line D.

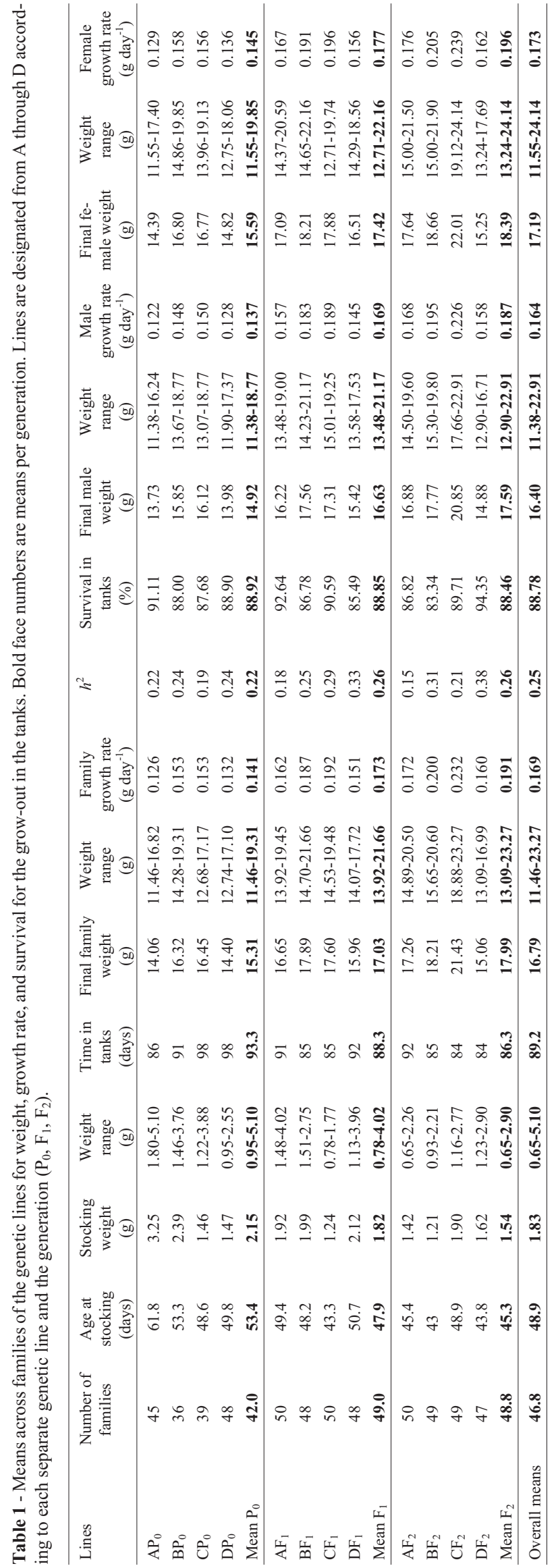




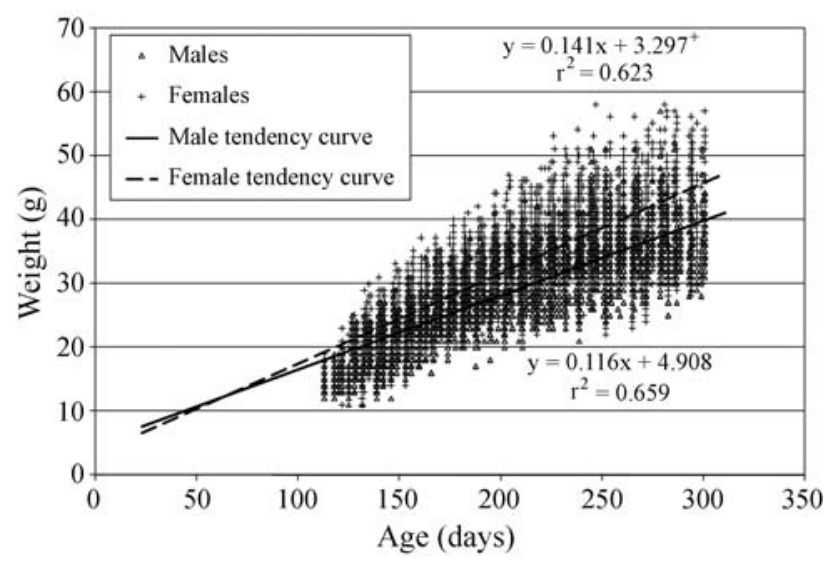

Figure 1 - Relationship between the weight of male and female Litopenaeus vannamei according to age. The equations and regression coefficient $\left(r^{2}\right)$ values are shown for both males (top) and females (bottom).

The highest weight and growth rate occurred in lines $\mathrm{B}$ and $\mathrm{C}(\mathrm{F}=1852.4, \mathrm{p}<0,0001)$, which were grown at higher temperatures and lower salinities (Figure 2). This pattern was maintained across generations. Regression analysis between the growth rate of the juvenile $L$. vannamei in the cages (from one to six-and-a-half weeks old) and the L. vannamei in the tanks (from six-and-a-half to fourteen weeks old) showed a highly significant relation$\operatorname{ship}(\mathrm{F}=73.31, \mathrm{p}<0.0001)$ but with very low values of regression and correlation coefficients $\left(r^{2}=0.117\right.$, $\rho=0.341)$. The average heritability $\left(h^{2}\right)$ for growth rate was calculated as $0.25 \pm 0.04$, with line and generation values ranging from 0.18 to 0.38 (Table 1). The improvement in the growth rate was $22.7 \%$ between $\mathrm{P}_{0}$ and $\mathrm{F}_{1}$ and $10.4 \%$ between $F_{1}$ and $F_{2}$, with an average per generation of $16.5 \%$. Similar improvements in growth rate occurred for both sexes, with the growth rate for females increasing $22.1 \%$ between $\mathrm{P}_{0}$ and $\mathrm{F}_{1}$ and 10.7 between $\mathrm{F}_{1}$ and $\mathrm{F}_{2}$, while for males the growth rate increased $23.4 \%$ between $\mathrm{P}_{0}$ and $F_{1}$ and $10.7 \%$ between $F_{1}$ and $F_{2}$. When comparing the growth rates for the different sexes at each generation at the time of harvest (110 to 135 days old) and at the end of the

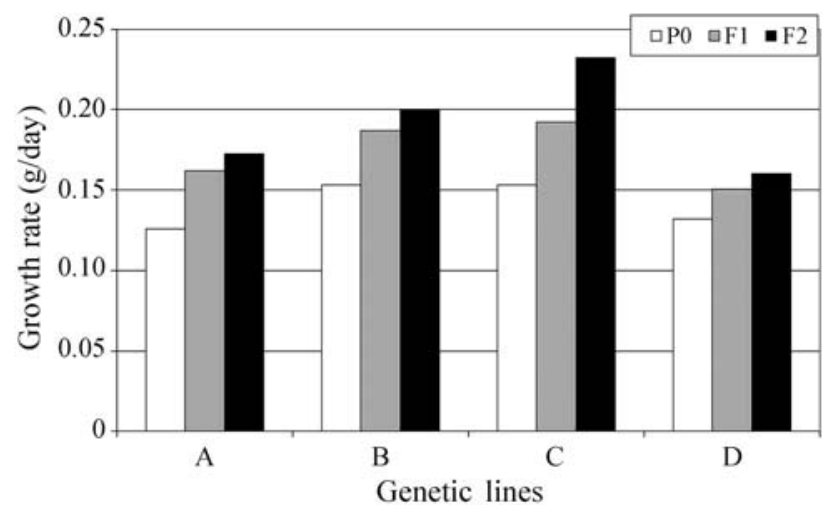

Figure 2 - Mean growth rate for all Litopenaeus vannamei families per generation in the four genetic lines studied. culture period (150 to 300 days old) we found that due faster growth at older age, females showed a greater gain in growth rate per generation than males (Figure 3). The improvement in the growth rate at older age was estimated as $8.8 \%$ between $\mathrm{P}_{0}$ and $\mathrm{F}_{1}$ and as $16.1 \%$ between $\mathrm{F}_{1}$ and $\mathrm{F}_{2}$, for an average per generation of $7.5 \%$, although there were statistically significant differences between the sexes (females $=13.8$ between $\mathrm{P}_{0}$ and $\mathrm{F}_{1}, 11.2$ between $\mathrm{F}_{1}$ and $\mathrm{F}_{2}$; males 2.4 between $\mathrm{P}_{0}$ and $\mathrm{F}_{1}, 3$ between $\mathrm{F}_{1}$ and $\mathrm{F}_{2}$ ). The average heritability for growth rate per generation varied slightly from $h^{2}=0.22$ for $\mathrm{P}_{0}$ to $h^{2}=0.26$ for $\mathrm{F}_{1}$ and $\mathrm{F}_{2}$. There was even greater variation between lines, with line $\mathrm{A}$ showing $h^{2}=0.18$, line $\mathrm{B} h^{2}=0.27$, line $\mathrm{C} h^{2}=0.23$ and line $\mathrm{D} h^{2}=0.32$. However, there was no correlation between heritability and growth rate since the lines with the lowest growth rate values (A and D) showed the lowest (line A) and highest (line D) mean $h^{2}$ values.

\section{Discussion}

Artificial selection has been widely used to improve growth performance and disease resistance in several species of penaeids. For example, Fjalestad et al. (1999) have found significant differences between both half- and fullsibs for harvest weight and survival of infection with Taura Syndrome Virus (TSV) in L. vannamei. These authors also reported a genetic gain of $4.4 \%$ for harvest weight and $12.4 \%$ for survival after a challenge test using a selection index that equally weighted both factors, and also estimated $h^{2}$ to be between 0.45 and 0.50 for harvest weight and 0.22 and 0.35 for survival.

Argue et al. (2002) established two L. vannamei breeding lines, one selected entirely for growth and the second selected on an index weighted $70 \%$ for TSV resistance and $30 \%$ for growth. After one generation of selection, the growth line gained $21 \%$ more weight than the unselected control. Based on half-sib correlation the estimate of $h^{2}$ value for growth was $0.84 \pm 0.43$. In the TSV line there was

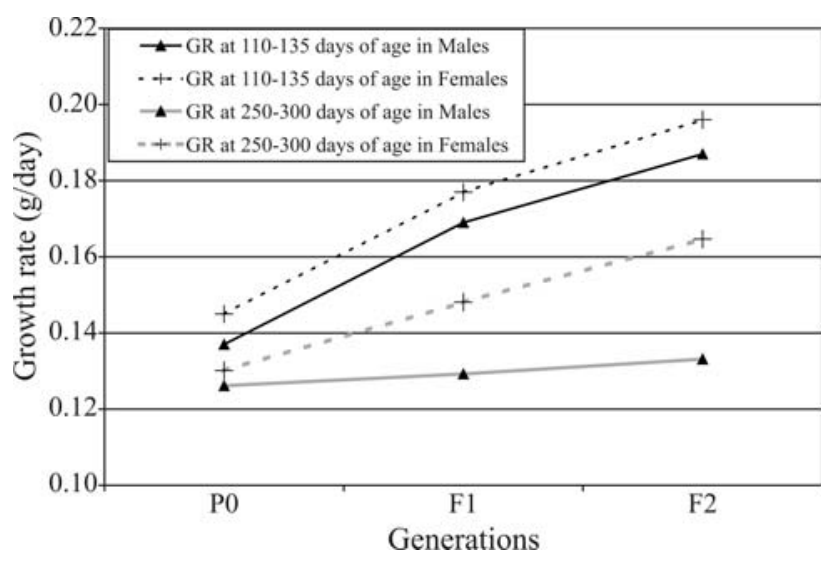

Figure 3 - Growth rate per generation in males and females at two different ages: 110-135 days (time of harvest and selection) and 250-300 days (when used for reproduction). 
an $18.4 \%$ increase in survival between selected and control L. vannamei, and the estimated $h^{2}$ value was 0.28 . However, the TSV selected line was $4.6 \%$ smaller than the control line and there was a negative genetic correlation between family growth and mean family survival after infection with TSV. Kenway et al. (2006) also found high values of estimated heritability for growth rate, with $h^{2}$ ranging from 0.48 to 0.55 in Penaeus monodon.

The gain in growth weight reported by Argue et al. (2002) is similar to that obtained in our study for the first generation of selection of $23.7 \%$ across the four lines, even though our $h^{2}$ value for growth (0.25) was significantly lower than the corresponding value (0.84) reported by Argue et al. (2002), and both were higher than the gain reported by Fjalestad et al. (1999). A similar increase in growth rate of $21 \%$ at the fifth generation of mass selection was reported by Goyard et al. (2002) for the penaeid $L$. stylirostris. These authors also investigated if early growth (mean weight $5 \mathrm{~g}$ ) was related to later growth (commercial size) and found that L. stylirostris which were larger at first weight check tended to weigh more after the grow-out period. Goyard et al. (2002) also estimated the realized heritability of growth to be relatively low (0.11), which was probably due to a loss of genetic variability (Bierne et al., 2000). In our study we also observed a significant relationship between early and late growth, suggesting that growth in both age periods is determined by the same genes.

Even though the lines used in our study have undergone a reduction in genetic variability following many years of closed cycle culture, as demonstrated by De Donato et al. (2005), our $h^{2}$ estimations for growth (0.25) were higher than those (0.11) estimated by Goyard et al. (2002). Furthermore, our $h^{2}$ estimates for growth were similar to those obtained for L. vannamei by Fjalestad et al. (1999) and by Benzie et al. (1997) for P. monodon, but much lower than that reported by Argue et al. (2002) for L. vannamei and Kenway et al. (2006) for P. monodon. Gitterle et al. (2005b) found that in L. vannamei the estimated $h^{2}$ for body weight at harvest varied substantially (from 0.01 to 0.54 ) between the different batches they studied, with overall $h^{2}$ estimates for body weight of 0.17 and 0.24 in the two genetic lines they used.

Peréz-Rostro and Ibarra (2003a,b) estimated $L$. vannamei mean final weight $h^{2}$ values between 0.17 and 0.20 and found not only that the mean growth rate $h^{2}$ values increased with age to 0.20 at 17 weeks, 0.24 at 23 weeks and 0.34 at 29 weeks of culture but also that there was differential growth rates at different ages, with families growing better when younger not necessarily growing better when older. It is important to point out that $h^{2}$ values are intrinsic to the population and species studied, depending on the genetic background and environmental conditions in which the animals were reared (Lynch and Walsh, 1998), so that our estimates should not be directly compared to those estimated in other studies.
Hetzel et al. (2000) designed a genetic program for the detection of quantitative trait loci (QTL) in $P$. japonicus, establishing high $(\mathrm{H})$ and low (L) body weight lines and found that the response to selection after one generation for growth at 185 days grow-out was an $8.3 \%$ improvement over the unselected mean. This increase was significantly less than that achieved in our study after an average of 89 days of grow-out but more similar to that obtained by us after 250 days to 300 days of culture. The average $h^{2}$ value estimated by Hetzel et al. (2000) was 0.234 , somewhat lower than that found in our study. Preston et al. (2002) followed up the study of Hetzel et al. (2000) and found that a fifth generation of selection in the same $\mathrm{H}$ line produced only a $10 \%$ mean gain in weight at first harvest, compared to the unselected control line.

Argue et al. (2002) reported that L. vannamei females were $12.7 \%$ larger than males at harvest after 154 days of culture, while Gitterle et al. (2005b) also found that the females were on average $4.5 \%$ heavier than males at the end of the grow-out period. Kenway et al. (2006) found that the female weight increased from $9.1 \%$ heavier than males at 30 weeks of grow-out to $35.9 \%$ at 54 weeks. In our study, females were $4.8 \%$ larger than males after 89 days of culture and $15 \%$ larger after 250 days to 300 days of culture, showing that the sex difference increases in larger $L$. vannamei. This greater increase in growth rate per generation in females than in males may suggest that the selection process in the studied populations was more efficient for females than males, especially at older ages, but this issue should be addressed in more detail.

Argue et al. (2002) suggested that even though the female to male sex ratio varied from $0.66: 1$ to $2.25: 1$, with a mean value of 1.04 females for each male, the heritability of sex ratio was zero, indicating that it was not feasible to select for a higher percentage of females. In our study, we also found a mean female to male sex ratio of $1.04: 1$, with a very similar range. However, the potential for artificial selection for this trait will depend on the genetic basis of sex determination in shrimps and prawns, which has not yet been established (Benzie, 1998).

On exposing L. vannamei to different temperature environments, Lester and Lawson (1990) obtained heritabilities for growth rate that ranged from 0.05 to 0.60 for late juveniles and from 0.35 to 0.53 for early juveniles. In these experiments, heritability estimates increased as temperature increased, but conversely Lester and Pante (1992) observed that as temperature decreased, heritabilities increased. De Tomás Kutz et al. (1998), analyzed the effect of experimental temperature on growth and survival for $L$. vannamei and found that the heritability for final weight increased as temperature increased. Peréz-Rostro et al. (1999) carried out several experiments to estimate the heritability and genetic correlations of L. vannamei growth traits for several larval and grow-out stages of development and found that heritabilities for the growth traits were influ- 
enced by maternal and environmental effects. In our study, there was variation in the estimated average heritability by line, with the $h^{2}$ value for line $\mathrm{C}$, grown at higher temperatures and lower salinities $\left(33{ }^{\circ} \mathrm{C}, 2.6 \%\right)$, being lower $\left(h^{2}=0.23\right)$ than for line $\mathrm{D}\left(h^{2}=0.32\right)$, grown at lower temperatures and higher salinities $\left(27^{\circ} \mathrm{C}, 3 \%\right)$, but no definite conclusion can be made since no correlation was found between growth rate and the estimated value of heritability.

Coman et al. (2002) examined genotype-environment interactions on survival and growth in Penaeus japonicus growing at different temperatures and found that the interactions for both traits were significant when differences in temperature were larger than $5{ }^{\circ} \mathrm{C}$ and that the effect was more pronounced on survival than on growth, suggesting that temperature by family interaction could affect the efficiency of artificial selection.

In the same $L$. vannamei populations as were studied by us, De Donato et al. (2005) reported that the gain in growth rate produced by mass selection was $14.5 \%$ after 11 generations. In our study, the family selection system produced twice as high a gain (33.1\%) in only two generations, demonstrating the effectiveness of the family selection system in improving growth rate in this strain of $L$. vannamei under the conditions stated. These results suggest that the potential for selection response of this population makes it a great resource for the future of shrimp aquaculture in the Americas.

\section{Acknowledgments}

We wish to acknowledge the extensive support provided by Rodolfo Luzardo and Federico Rivero in carrying out this study and for allowing the publication of this information. They invested in genetic improvement techniques several years ago, and time has proven that their strategy was a wise investment. We also would like to acknowledge Harvey Persyn, Amber Persyn, Reginald Markham and Max Padron, who were all instrumental in the foundation and initial development of the project.

\section{References}

AQUACOP (1983) Constitution of broodstock, maturation, spawning and hatching system for penaeid shrimps in the Centre Oceanologique du Pacifique. In: McVey JP (ed) CRC Handbook of Mariculture, v. 1: Crustacean Aquaculture. CRC Press, Miami, pp 105-121.

Argue BJ, Arce SM, Lotz JM and Moss SM (2002) Selective breeding of Pacific white shrimp (Litopenaeus vannamei) for growth and resistance to Taura Syndrome Virus. Aquaculture 204:447-460.

Associação Brasileira de Criadores de Camarão (2003) Genetic improvement of Litopenaeus vannamei in Brazil. Glob Aquacult Advoc 6:27-29.

Benzie JAH (1998) Penaeid genetics and biotechnology. Aquaculture 164:23-47.
Benzie JAH, Kenway M and Trott L (1997). Estimates for the heritability of size in juvenile $P$. monodon from half-sib matings. Aquaculture 152:49-53.

Bierne N, Beuzart I, Vonau V, Bonhomme F and Bédier E (2000) Microsatellite-associated heterosis in hatchery-propagated stocks of the shrimp Penaeus stylirostris. Aquaculture 184:203-219.

Boldman KG, Van Vleck LD, Kriese LM and Kachman S (1995) MTDFREML: User's Guide. Department of Agriculture/ Agricultural Research Service, Washington, DC 112 pp.

CENIACUA (1999) Colombia's closed-cycle program for penaeid shrimp genetic selection and improvement. Glob Aquacult Advoc 2:71, 83-84.

Coman G, Crocos P, Preston N and Fielder D (2002) Effect of genotype-environment interaction on the survival and growth of the Kuruma shrimp Penaeus japonicus. Aquaculture 204:197-198.

De Donato M, Manrique R, Ramirez R, Mayer L and Howell C (2005) Mass selection and inbreeding effects on a cultivated strain of Penaeus (Litopenaeus) vannamei in Venezuela. Aquaculture 247:159-167.

De Tomás Kutz AJ, Taylor JF, Lawrence AL, Neill WH and Davis SK (1998) Quantitative genetic analysis of growth and survival in Penaeus vannamei versus temperature. Proceedings of the $1^{\text {st }}$ Latin American Shrimp Culture Congress, Panama.

FAO (2003) Health management and biosecurity maintenance in white shrimp (Penaeus vannamei) hatcheries in Latin America. FAO Fisheries Technical Paper n. 450. FAO, Rome, $62 \mathrm{pp}$.

Fjalestad KT, Carr WH, Lotz J, Sweeney JN and Gjedrem T (1999) Genetic variation and selection response in body weight and disease resistance in Pacific white shrimp (Penaeus vannamei). Aquaculture 204:198.

Gitterle T, Rye M, Salte R, Cock J, Johansen H, Suarez JA, Lozano C and Gjerde B (2005b) Genetic (co)variation in harvest body weight and survival in Penaeus (Litopenaeus) vannamei under standard commercial conditions. Aquaculture 243:83-92.

Gitterle T, Salte R, Gjerde B, Cock J, Johansen H, Salazar M, Lozano C and Rye M (2005a) Genetic (co)variation in resistance to white spot syndrome virus (WSSV) and harvest weight in Penaeus (Litopenaeus) vannamei. Aquaculture 246:139-149.

Gjedrem T (1997) Selective breeding to improve aquaculture production. World Aquacult 22:33-45.

Goswani U, Goswani SC and Dalal SG (1990) Morphometric studies in Penaeus merguiensis from Ratnagiri waters for selection of the broodstock in genetic improvement programmes. J Ind Fish Assoc 20:1-5.

Goyard E, Patrois J, Peignon JM, Vanaa V, Dufour R, Viallon J and Bédier E (2002) Selection for better growth of Penaeus stylirostris in Tahiti and New Caledonia. Aquaculture 204:461-468.

Hernández R (2002) Shrimp genetic improvement in Mexico. Glob Aquacult Advoc 5:43-44.

Hetzel DJS, Crocos PJ, Davis GP, Moore SS and Preston NC (2000) Response to selection and heritability for growth in the Kuruma prawn, Penaeus japonicus. Aquaculture 181:215-223.

Huang CM, Tsai MY and Liao IC (1990) Morphometric studies on choice of broodstock for genetic improvement in 
Penaeus penicillatus. In: Hirano R and Hanyu I (eds) The Second Asian Fisheries Forum. Asian Fisheries Society, Manila, pp 523-526.

Hulata G (2001) Genetic manipulations in aquaculture: A review of stock improvement by classical and modern technologies. Genetica 111:155-173.

Kenway M, Macbeth M, Salmon M, McPhee C, Benzie J, Wilson $\mathrm{K}$ and Knibb W (2006) Heritability and genetic correlations of growth and survival in black tiger prawn Penaeus monodon reared in tanks. Aquaculture 259:138-145.

Lester LJ (1983) Developing a selective breeding program for penaeid shrimp mariculture. Aquaculture 33:41-50.

Lester LJ (1988) Difference in larval growth among families of Penaeus stylirostris Stimpson and Penaeus vannamei Boone. Aquacult Fish Manage 19:243-251.

Lester LJ and Lawson KS (1990) Inheritance of size as estimated by principal component analysis at two temperatures in Penaeus vannamei. Aquaculture 85:323.

Lester LJ and Pante MJR (1992) Penaeid temperature and salinity responses. In: Fast AW and Lester LJ (eds) Marine Shrimp Culture: Principles and Practices. Elsevier, Amsterdam, pp 515-534.

Lynch M and Walsh B (1998) Genetics and Analysis of Quantitative Traits. Sinauer Associates Inc., Sunderland, 980 pp.

Pérez-Rostro CI and Ibarra AM (2003a) Quantitative genetic parameter estimates for size and growth rate traits in Pacific white shrimp, Penaeus vannamei (Boone 1931) when reared indoords. Aquacult Res 34:543-553.

Pérez-Rostro CI and Ibarra AM (2003b) Heritabilities and genetic correlations of size traits at harvest size in sexually dimorphic Pacific white shrimp (Litopenaeus vannamei) grown in two environments. Aquacult Res 34:1079-1085.

Pérez-Rostro CI, Ramírez JL and Ibarra AM (1999) Maternal and cage effects on genetic parameter estimation for Pacific white shrimp Penaeus vannamei Boone. Aquacult Res 30:1-13.

Preston NP, Croscos PJ and Keys S (2002) Improving the growth rates of farm stocks of Panaeus japonicus through selective breeding. Aquaculture 204:239.

Wyban JA (1992) Selective breeding of specific pathogen-free (SPF) shrimp for high health and increased growth. In: Fulks W and Main KL (eds) Diseases of Cultured Penaeid Shrimp in Asia and the United States. The Oceanic Institute, Honolulu, pp 92-96.

\section{Internet Resources Section}

Fisheries Global Information System, http:/www.fao.org/figis/ servlet/static?dom $=$ root\& $\mathrm{xml}=$ tseries/index.xml $($ January $31,2007)$.

Associate Editor: Luiz Lehmann Coutinho

License information: This is an open-access article distributed under the terms of the Creative Commons Attribution License, which permits unrestricted use, distribution, and reproduction in any medium, provided the original work is properly cited. 